\title{
Editorial
}

\section{Keep the Fuel Burning}

A few weeks back I was participating in a thesis defense. The topic was a far cry from chironomid work, but one message that came out of the defense is relevant to all of us, so bear with me a moment. The candidate had found that a very well-researched lizard was capable of vocalizing ultrasonically - something previously unknown to science. Towards the end of the defense, one of the referees asked the candidate how it was possible that this behavior was as-of-yet undescribed, especially considering that this lizard is considered as a model organism for reptilian studies. The candidate did well discussing several typical reasons - funding, time, technological needs, etc. The conversation took a turn, though; we began discussing how findings like these make the field of scientific research so fascinating. As researchers, I am certain we can all relate to this desire to discover; knowing that there is always "more" is the fuel that ignites our passion.

These new discoveries not only keep us going and keep our field fresh, but also act to attract new researchers to our community. I know that many students in my Entomology and Invertebrate Zoology courses are astounded by how easy (barring time and funding) it is to contribute new knowledge to science, particularly when considering insects and other invertebrates. This knowledge provides enough fuel for some of these students to continue on a research-based career path, and is likely what initially hooked many of us.

A quick glance through the many excellent contributions to this year's volume of CHIRONOMUS is evidence that this fuel continues to burn strong in our chironomid community. Step back to consider how fascinating it is that we can still easily discover new species and genera of chironomids (e.g. Andersen et al. 2017, Epler 2017). Then, when considering the species we do already know, bear in mind how much left there is to learn about their life history, development, home range, and patterns of richness (e.g. Baranov and Nekhaev 2017, Kuper 2017, Namayandeh and Beresford 2017). Lastly, when we utilize relatively new techniques, such as abilities to compare DNA sequences, or as we collect, curate, and closely study new specimens, we can add to or alter previous documentation and descriptions (e.g. Martin 2017, Lin and Wang 2017). Moral of the story - there is always more to discover. What an exciting field we have chosen.

We hope that you enjoy this year's collection of articles and that some of them aid in your research endeavors. Keep that fuel burning!

Alyssa M. Anderson

Department of Biology, Chemistry, Physics, and Mathematics, Northern State University, Aberdeen, South Dakota, USA.E-mail: alyssa.m.anderson@northern.edu

\section{References:}

Andersen, T., Mendes, H.F., and Pinho L.C. 2017. Two new Neotropical Chironominae genera (Diptera: Chironomidae). - CHIRONOMUS Journal of Chironomidae Research. 30: 26-54. DOI: http://dx.doi. org/10.5324/cjcr.v0i30.2029

Baranov, V. and Nekhaev, I. 2017. Impact of the bird-manure caused eutrophication on the abundance and diversity of chironomid larvae (Diptera; Chironomidae) in lakes of the Bolshoy Aynov Island (Russia, Barents Sea). - CHIRONOMUS Journal of Chironomidae Research. 30: 72-75. DOI: http://dx.doi. org/10.5324/cjcr.v0i30.2260

Epler, J.H. 2017. An annotated preliminary list of the Chironomidae (Diptera) of Zurquí, Costa Rica. CHIRONOMUS Journal of Chironomidae Research. 30: 4-18. DOI: http://dx.doi.org/10.5324/cjcr. v0i30.2240

Kuper, J. 2017. Life cycle of natural populations of Metriocnemus (Inermipupa) carmencitabertarum Langton \& Cobo 1997 (Diptera: Chironomidae) in The Netherlands: indications for a southern origin? - CHIRONOMUS Journal of Chironomidae Research. 30: 55-66. DOI: http://dx.doi.org/10.5324/cjcr. $\underline{\mathrm{v} 0 \mathrm{i} 30.2268}$ 
Lin, X. and Wang X. 2017. A redescription of Zavrelia bragremia Guo \& Wang, 2007 (Diptera: Chironomidae). - CHIRONOMUS Journal of Chironomidae Research. 30: 67-71. DOI: http://dx.doi.org/10.5324/ cjcr.v0i30.2345

Martin, J. 2017. Chironomus strenzkei Fittkau, 1968 is a junior synonym of C. striatipennis Kieffer, 1910. - CHIRONOMUS Journal of Chironomidae Research. 30: 19-25. DOI: http://dx.doi.org/10.5324/cjcr. v0i30.2190

Namayandeh, A. and Beresford D.V. 2017. New range extensions for the Canadian Chironomidae fauna from two urban streams. CHIRONOMUS Journal of Chironomidae Research. 30: 76-80. DOI: http:// dx.doi.org/10.5324/cjcr.v0i30.2415 